\title{
Equatorial scintillations in relation to the development of ionization anomaly
}

\author{
S. Ray ${ }^{1}$, A. Paul ${ }^{2}$, and A. DasGupta ${ }^{1,2}$ \\ ${ }^{1}$ S. K. Mitra Center for Research in Space Enviornment, University of Calcutta, Calcutta, India \\ ${ }^{2}$ Institute of Radio Physics and Electronics, University of Calcutta, Calcutta, India
}

Received: 1 September 2005 - Revised: 19 December 2005 - Accepted: 2 February 2006 - Published: 3 July 2006

Part of Special Issue "The 11th International Symposium on Equatorial Aeronomy (ISEA-11), Taipei, May 2005”

\begin{abstract}
The irregularities in the electron density distribution of the ionosphere over the equatorial region frequently disrupt space-based communication and navigation links by causing severe amplitude and phase scintillations of signals. Development of a specification and forecast system for scintillations is needed in view of the increased reliance on spacebased communication and navigation systems, which are vulnerable to ionospheric scintillations. It has been suggested in recent years that a developed equatorial anomaly in the afternoon hours, with a steep gradient of the F-region ionization or Total Electron Content (TEC) in the region between the crest and the trough, may be taken as a precursor to scintillations on transionospheric links. Latitudinal gradient of TEC measured using Faraday Rotation technique from LEO NOAA 12/14 transmissions during the afternoon hours at Calcutta shows a highly significant association with L-band scintillations recorded on the INMARSAT link, also from Calcutta, during the equinoxes, August through October 2000, and February through April 2001.
\end{abstract}

The daytime equatorial electrojet is believed to control the development of the equatorial anomaly and plays a crucial role in the subsequent development of F-region irregularities in the post-sunset hours. The diurnal maximum and integrated value (integrated from the time of onset of plasma influx to off-equatorial latitudes till local sunset) of the strength of the electrojet in the Indian longitude sector shows a significant association with post-sunset L-band scintillations recorded at Calcutta during the two equinoxes mentioned earlier.

Generation of equatorial irregularities over the magnetic equator in the post-sunset hours is intimately related to the variation of the height of the F-layer around sunset. Ionosonde data from Kodaikanal, a station situated close to the magnetic equator, has been utilized to calculate the vertical drift of the F-layer over the magnetic equator for

Correspondence to: A. DasGupta

(adg1bkpr@hotmail.com) the period August through October 2000. The post-sunset F-region height rise over the magnetic equator shows a remarkable correspondence with the occurrence of scintillations at Calcutta located near the northern crest of the equatorial anomaly.

Existence of a flat-topped ionization distribution over the magnetic equator around sunset has been suggested as a possible indication of occurrence of post-sunset scintillations. Width of the latitudinal distribution of ionization obtained from DMSP satellite shows some correspondence with postsunset L-band scintillations. During the period of observation of the present study (August through October 2000, and February through April 2001), it has been observed that although the probability of occurrence of scintillations is high on days with flat-topped ion density variation over the equator, there are cases when no scintillations were observed even when a pronounced flat top variation was recorded.

Keywords. Ionosphere (Equatorial ionosphere; Ionospheric irregularities; Modeling and forecasting)

\section{Introduction}

Space Weather has become an important area of research in recent years because of its impact on satellite-based systems. A part of the domain of Space Weather covers the altitude range $100-2000 \mathrm{~km}$. This region of the atmosphere is a very sensitive part of the Earth-Sun system. Although the climatology of the Earth's upper atmosphere to solar and geomagnetic effects has been extensively studied, the day-to-day variability, or in other words, the "weather" of this region of the Earth's near-space environment is yet to be fully understood. A very important component of the International Space Weather program is concerned with the development of forecasting and nowcasting techniques for equatorial ionospheric irregularities. For designing a fail-safe communication or navigation system, prediction of the regular as well

Published by Copernicus GmbH on behalf of the European Geosciences Union. 
as irregular features of ionization in the upper atmosphere is essential.

The Earth's ionized upper atmosphere often becomes turbulent and develops electron density irregularities. In the presence of a relative motion between the satellite, the ionosphere and the receiver, the received signal exhibits amplitude and phase scintillations. Amplitude scintillations cause signals to fade below the average level. When the depth of fading exceeds the fade margin of a receiver, the signal becomes buried in noise and signal loss and cycle slips are encountered. Phase scintillations induce a frequency shift and when this shift exceeds the phase locked loop bandwidth, the signal is lost and the receiver spends valuable time reacquiring the signal. Overall, in the presence of scintillations, the performance of communication and navigation systems is degraded.

These propagation effects are most severe around the magnetic equator and the crests of the equatorial anomaly in the early evening hours. The morphology of the equatorial ionosphere is quite different from that at other latitudes because the magnetic field $\boldsymbol{B}$ is nearly parallel to the Earth's surface. During daytime, the E-region dynamo electric field $\boldsymbol{E}$ is eastward. Due to the "fountain effect", the resulting $\boldsymbol{E} \times \boldsymbol{B}$ drift transports F-region plasma upward at the magnetic equator. The uplifted plasma then moves along $\boldsymbol{B}$ in response to gravity and pressure-gradient forces. As a result, the equatorial anomaly is formed with minimum F-region ionization density at the magnetic equator and maxima at the two crests approximately $15^{\circ}$ to $20^{\circ}$ in magnetic latitude to the north and south.

Near sunset, plasma densities and dynamo electric fields in the E-region decrease, and the equatorial anomaly begins to weaken. However, at this local time, a dynamo develops in the F-region. Polarization charges within conductivity gradients at the terminator enhance the eastward electric field after sunset. The post-sunset electric field moves the ionospheric plasma upward, allowing the equatorial anomaly crests to intensify. After sunset, F-region dynamo currents are no longer subject to the shorting effect of the conducting E-layer to the north and south of the magnetic equator. Polarization fields are thus able to drive the F-layer upwards. Eventually the electric field turns westward, causing plasma to drift downward. Just before the reversal at the time of sunset, the field is much enhanced (Rishbeth, 1971). This is called the postsunset or the pre-reversal enhancement of the eastward electric field. The pre-reversal enhancement holds the key to the formation of irregularities. This causes a rapid uplifting of the F-region, and steepens the bottomside gradient leading to the Rayleigh-Taylor (R-T) instability. Soon after sunset, vertical plasma density gradients form in the bottom side of the $\mathrm{F}$ layer. The upward density gradient is opposite in direction to the gravitational force. This configuration is R-T unstable and allows plasma density irregularities to form. These irregularities can grow to become large ionospheric depletions often called equatorial plasma bubbles. Recent investi- gations leave open the scientific question of whether an enhancement in upward $\boldsymbol{E} \times \boldsymbol{B}$ drift is necessary and sufficient or simply necessary for creating the ambient conditions conducive to scintillation occurrence (Anderson et al., 2004). It is suggested that there exists a "threshold" in $\boldsymbol{E} \times \boldsymbol{B}$ drift that determines whether subsequent scintillation activity will occur or not. This implies that the $\boldsymbol{E} \times \boldsymbol{B}$ drift velocity needs to be above a certain value before bottom-side spread $\mathrm{F}$ can percolate upward and form equatorial bubbles, and the 'seeding' mechanism is always present and all that is required is for the $\boldsymbol{E} \times \boldsymbol{B}$ drift velocity to be greater than some critical value.

Development of a specification and forecast methodology for scintillations is needed in view of the increased reliance on space-based communication and navigation systems, which are vulnerable to ionospheric scintillations. It has been suggested in recent years that there is a correspondence between the development of the electrojet during the daytime and the post-sunset enhancement of the eastward electric field although the physical mechanism connecting the two is not fully clear. The equatorial electrojet controls the development of the equatorial anomaly through the fountain effect. Under strong electrojet conditions, the anomaly is developed in the afternoon hours with a steep gradient of the F-region ionization or Total Electron Content (TEC) in the region between the crest and the trough. Thus a measurement of the latitudinal gradient of electron content would provide an indication of the post-sunset eastward electric field enhancement and could validate the above suggestion. A developed equatorial anomaly in the afternoon hours may then be taken as a precursor to scintillations on transionospheric links (Raghavarao et al., 1988). In the early days of satellite beacon observations, Faraday Rotation measurements with transmissions from Low Earth Orbiting (LEO) satellites have been utilized to show that the TEC exhibits a pronounced latitudinal variation similar to that observed with the F-region maximum ionization (NmF2) (Basu and DasGupta., 1967). In recent years however, such measurements have been rare because of non-availability of suitable satellite transmissions. The only available satellites of the NOAA series transmitting plane-polarized signals at $136 / 137 \mathrm{MHz}$ may however be used to study the above latitudinal features for TEC. By combining the latitudinal gradient of TEC measured in the region between the trough and the crest of the equatorial anomaly in the local afternoon hours, using transmission from LEO NOAA, with post-sunset equatorial scintillations on geostationary L-band link, both measured at Calcutta situated under the northern crest of the equatorial anomaly, the existence of any correlation between the two phenomena could be examined.

Intensity of scintillations on geostationary links is usually quantified by calculating the $S_{4}$ index from the carrier signal. $S_{4}$ index is defined as the standard deviation of the normalized signal intensity. Geostationary links sample a fixed point in space and when irregularities drift across the 
fixed ionospheric pierce point, scintillations are observed on the ground diffraction pattern. GPS signals employ spread spectrum technique and the carrier is the product of reconstruction in the receiving equipment. Hence both amplitude and phase scintillations on any GPS link depend on receiver properties. Scintillation indices calculated in this case are different from that on a geostationary link. Furthermore, intense scintillations may be observed on a GPS link looking "end-on" through field-aligned bubbles.

The development of the equatorial anomaly is mainly controlled by the equatorial electrojet. The strength of the electrojet could be measured by the differences between the hourly inequalities $(\Delta \mathrm{H})$ of the horizontal component $(\mathrm{H})$ of the geomagnetic field at a station near the magnetic equator, situated close to the axis of the equatorial electrojet, and another station located away from the magnetic equator outside the electrojet region. This prevents any non-ionospheric contribution to the magnetic field variation, e.g. magnetospheric contributions.

Enhanced electric field raises the electron density to the topside and reverses the process of normal decay of the anomaly. Sometimes, the post sunset anomaly becomes more developed than the daytime phenomenon. The equatorial anomaly is not confined to the maximum ionization height $h m \mathrm{~F} 2$, but extends up to several hundred kilometers in the topside of the ionosphere. The locus of the ionization crests in the topside lies on a field-line. A larger post sunset enhancement of the eastward electric field may raise the apex of the field line at the equator to heights above the nominal altitude of satellites $(840 \mathrm{~km})$ like DMSP. As the satellite moves across the equator, the ionization density would then either show a flat top or two crests at off-equatorial latitudes. It has been suggested that an idea about the occurrence of scintillations may be obtained from the latitudinal distribution of ion density by DMSP (Basu et al., 2002).

This paper presents parameters, measured by different techniques, as precursors to post sunset equatorial scintillations on transionospheric geostationary links at a station situated beneath the northern crest of the equatorial anomaly during the maximum of the last solar cycle in 2000-2001. These methods could be summarized as 1) measuring the latitudinal gradient of TEC in the region between the trough and the crest of the equatorial anomaly from the Faraday rotation of a plane polarized signal from a low Earth orbiting satellite, 2) calculating the diurnal maximum and integrated value of the strength of the equatorial electrojet in the Indian longitude sector, 3) estimation of the post sunset F-region height rise over the magnetic equator, and 4) determination of the width of the flat top from the latitudinal distribution of ionization density in the topside F-region obtained from satellites like DMSP. A reliable forecast of scintillations in the post-sunset hours at this geophysically sensitive region of the Earth would serve as a benchmark for the International Space Weather program.

\section{Data}

Transmission from a low Earth orbiting (LEO) satellite is more suitable for studying the latitudinal variation of TEC. The Faraday Rotation of plane polarized VHF signal at 136/137 MHz from the sun-synchronous LEO NOAA 12/14 (altitude: $850 \mathrm{~km}$ ) recorded at Calcutta (lat: $22.58^{\circ} \mathrm{N}$ long: $88.38^{\circ}$ E geographic; dip: $32^{\circ} \mathrm{N}$ ) during August through October 2000 and February through April 2001, both periods of high sunspot numbers, were utilized to obtain a measure of development of the anomaly. The latitudinal gradient of TEC between $15^{\circ}-18^{\circ} \mathrm{N}$ geographic was routinely scaled from the ascending (south-to-north) orbit of NOAA 12 and NOAA 14 in the afternoon hours (16:30 LT for NOAA 12 and 16:20 LT for NOAA 14). TEC data from NOAA were available for 36 days during August through October 2000 and 42 days in February through April 2001. VHF (FLEETSATCOM, $244 \mathrm{MHz}$ ) satellite transmission has been routinely monitored from Calcutta since 1980 and L-band (INMARSAT, $1.6 \mathrm{GHz}$ ) since 1994 to study the occurrence of scintillations at this station. The receivers were calibrated at least once a week following Basu and Basu (1989). The scintillation data was scaled to obtain Scintillation Index (SI (dB)) and $\mathrm{S}_{4}$ following Whitney et al. (1969). The anomaly gradients calculated from NOAA records have been combined with postsunset equatorial scintillations observed from Calcutta with INMARSAT during the above period to study the existence of any correlation. The intensity of post-sunset L-band scintillations was quantified by calculating the $15-\mathrm{min} \mathrm{S}_{4}$ index. Since the VHF scintillation records during the period under consideration were mostly saturated with $S_{4} \sim 1$, the maximum $\mathrm{S}_{4}\left(\mathrm{~S}_{4 \max }\right)$ at L-band for a particular night was used to study the day-to-day variability of the intensity of scintillations.

Changes in the geomagnetic field $\mathrm{H}$ observed at any equatorial station need not necessarily be changes in electrojet strength. Magnetospheric changes, having a source far away from the Earth, are also recorded. Hence an equatorial station under the electrojet will have about the same magnetospheric contribution as a low latitude station outside the equatorial electrojet influence. On the other hand, the ionospheric effects at these two locations would be different. Thus the subtraction of $\mathrm{H}$ values at the low latitude station from the $H$ values at the equatorial station would yield a quantity, which would be free from magnetospheric effects. In the Indian subcontinent, geomagnetic data from Tirunelveli (lat: $8.67^{\circ} \mathrm{N}$, long: $77.82^{\circ} \mathrm{E}$ geographic; dip: $0.5^{\circ} \mathrm{N}$ ) situated within the equatorial electrojet and Alibag (lat: $19.00^{\circ} \mathrm{N}$, long: $72.83^{\circ} \mathrm{E}$ geographic; dip: $24.75^{\circ} \mathrm{N}$ ) outside the equatorial electrojet were used to obtain an estimate of the equatorial electrojet. Denoting the hourly inequality of the horizontal component of the geomagnetic field at Tirunelveli by $\Delta \mathrm{H}_{T}$ and that at Alibag by $\Delta \mathrm{H}_{A}$, a measure of the electrojet is given by $\left(\Delta \mathrm{H}_{T}-\Delta \mathrm{H}_{A}\right)$ (Kane, 1973; Rastogi and Klobuchar, 1990). Geomagnetic data were available for 


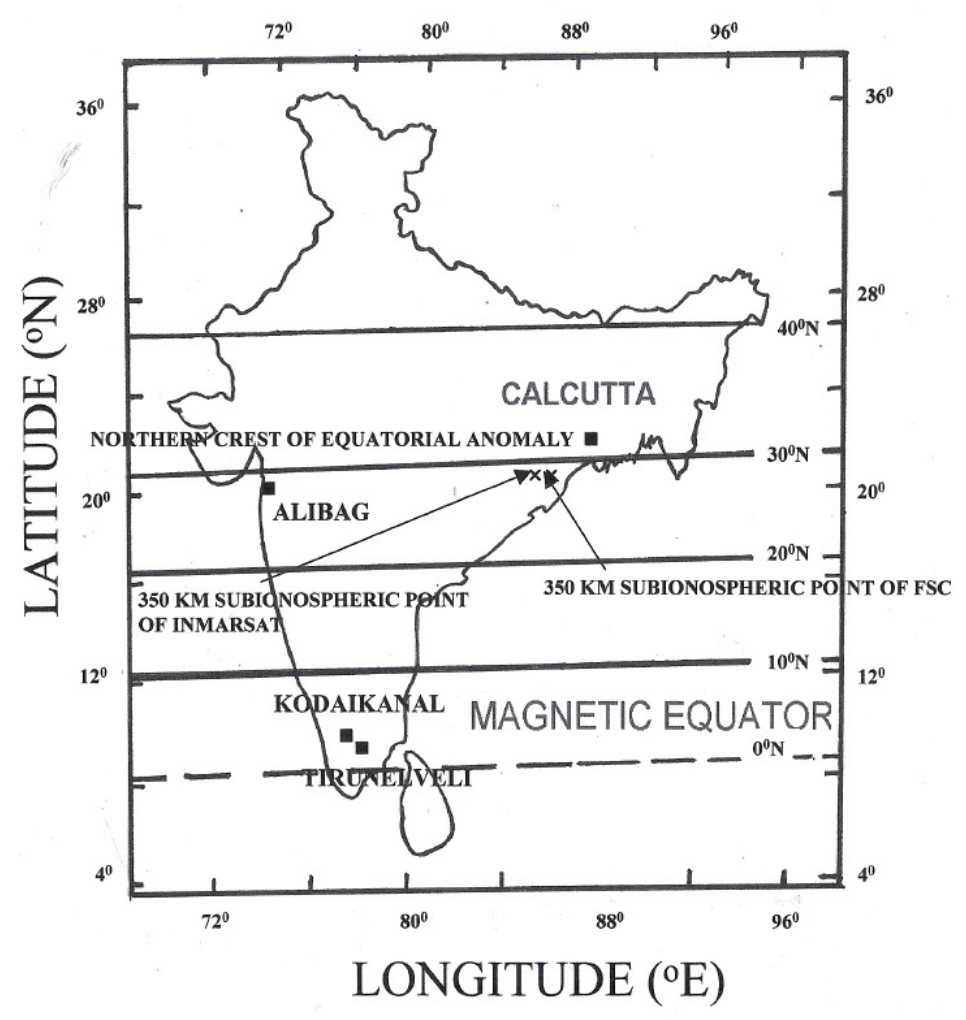

Fig. 1. Map of India showing locations of the stations Calcutta (lat: $22.58^{\circ} \mathrm{N}$ long: $88.38^{\circ} \mathrm{E}$ geographic; dip: $32^{\circ} \mathrm{N}$ ), Alibag (lat: $19.00^{\circ} \mathrm{N}$ long: $72.83^{\circ}$ E geographic; dip: $24.75^{\circ} \mathrm{N}$ ), Kodaikanal (lat: $10.23^{\circ} \mathrm{N}$ long: $77.47^{\circ}$ E geographic; dip: $1.5^{\circ} \mathrm{N}$ ) and Tirunelveli $\left(\right.$ lat: $8.67^{\circ} \mathrm{N}$ long: $77.82^{\circ} \mathrm{E}$ geographic; dip: $0.5^{\circ} \mathrm{N}$ ). The location of the magnetic equator and the northern crest of the equatorial anomaly around $30^{\circ} \mathrm{N}$ dip are also shown. Dip lines at $10^{\circ}$ intervals from the magnetic equator to $40^{\circ} \mathrm{N}$ dip are included. The $350-\mathrm{km}$ subionospheric points of the geostationary satellites FLEETSATCOM $\left(71^{\circ} \mathrm{E}\right)$ (lat: $21.10^{\circ} \mathrm{N}$ long: $87.25^{\circ}$ E geographic; dip: $\left.28.65^{\circ} \mathrm{N}\right)$ and INMARSAT $\left(65^{\circ} \mathrm{E}\right)($ lat: $21.08^{\circ} \mathrm{N}$ long: $86.59^{\circ} \mathrm{E}$ geographic; dip: $28.74^{\circ} \mathrm{N}$ ) from Calcutta are indicated by arrows.

85 days during August through October 2000 and 89 days during February through April 2001. Two parameters were used to correlate the strength of the daytime equatorial electrojet with post-sunset scintillations at Calcutta. One of them was the diurnal maximum value of the inequality represented by $\Delta\left(\mathrm{H}_{T}-\mathrm{H}_{A}\right)_{\max }$ while the other was the integrated value of the same represented by $\Delta\left(\mathrm{H}_{T}-\mathrm{H}_{A}\right)_{\text {intg. }}$. In the second case, the integration was performed from the time of onset of plasma transport from the magnetic equator to off-equatorial latitudes around $08 \mathrm{LT}$ till local sunset.

In order to examine the correspondence between the daytime electron density gradient, post sunset F-region height rise, and generation of ionospheric irregularities, ionosonde data from Kodaikanal (lat: $10.23^{\circ} \mathrm{N}$, long: $77.47^{\circ} \mathrm{E}$ geographic; dip: $1.5^{\circ} \mathrm{N}$ ), a station situated close to the magnetic equator, was utilized along with ground-based satellite beacon records of Calcutta. During the period August through October 2000, Kodaikanal $h^{\prime} F$ data was available on 72 days. From the $h^{\prime} F$ values, the vertical plasma rise velocity was calculated over the interval from local sunset to 20:00 LT. Because of the longitudinal separation, no point-to-point correspondence should be expected between the post sunset F-region height rise over Kodaikanal and scintillations at Calcutta. However, the general behavior is likely to be more or less the same.

DMSP satellites in sun synchronous polar orbits could measure the latitudinal variation of in-situ ion density at $840 \mathrm{~km}$. The satellite DMSP F13 is in a roughly dawn-dusk orientation covering the magnetic latitude range $\pm 30^{\circ}$ once near local sunset at Calcutta. The ion density data from DMSP at 4-s resolution are available at http://cindispace. utdallas.edu/DMSP/. Data was available for 83 days of $\mathrm{Au}-$ gust through October 2000 and 79 days of February through April 2001.

\section{Results}

3.1 Latitudinal gradient of Total Electron Content (TEC) and scintillations

Figure 1 shows the location of the stations Calcutta (lat: $22.58^{\circ} \mathrm{N}$ long: $88.38^{\circ} \mathrm{E}$ geographic; dip: $32^{\circ} \mathrm{N}$ ), Alibag 


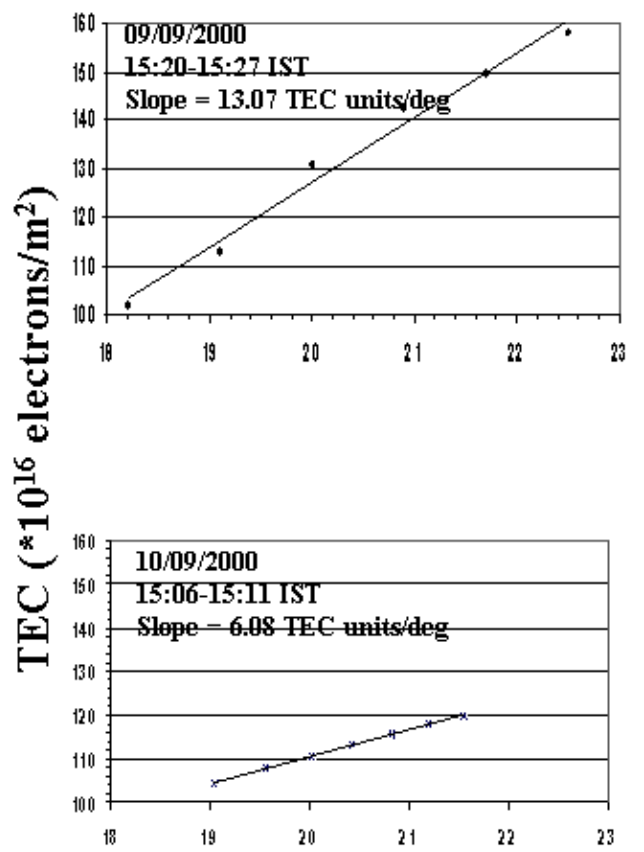

(a)

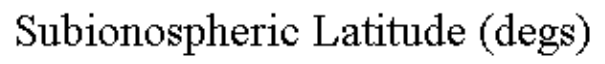

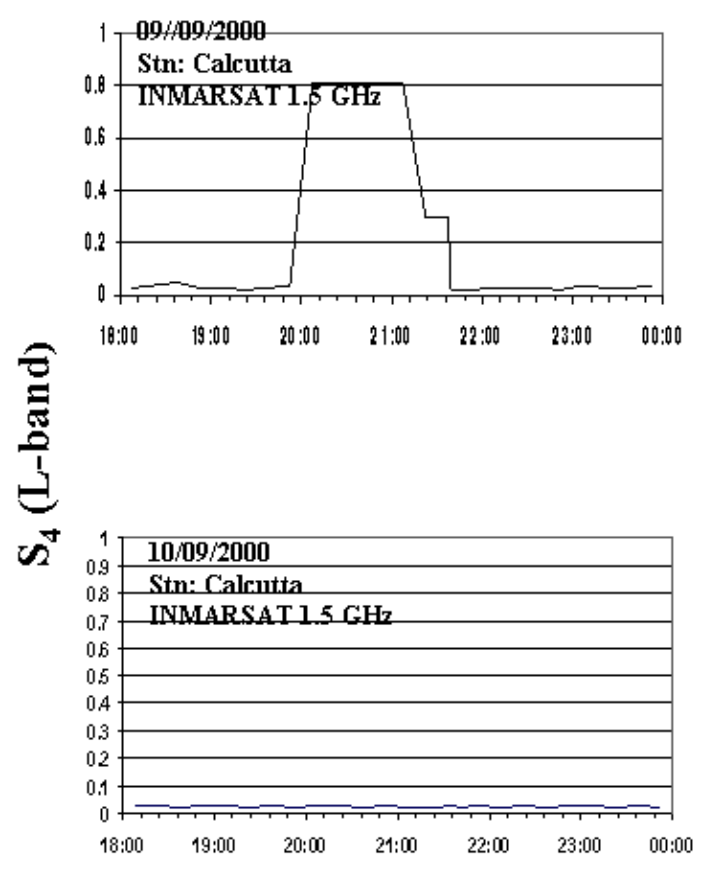

(b)

Fig. 2. (a) Latitudinal variation of Equivalent Vertical Total Electron Content (TEC $\left(* 10^{16}\right.$ electrons $\left./ \mathrm{m}^{2}\right)$ ) measured from Faraday Rotation data recorded at Calcutta using LEO NOAA14 transmission at $137 \mathrm{MHz}$ on two consecutive days 9 and 10 September 2000. (b) Variation of $\mathrm{S}_{4}$ index of L-band scintillations at Calcutta on the above two days during 18:00 IST (=UT+05:30) to midnight.

(lat: $19.00^{\circ} \mathrm{N}$ long: $72.83^{\circ} \mathrm{E}$ geographic; dip: $24.75^{\circ} \mathrm{N}$ ), Kodaikanal (lat: $10.23^{\circ} \mathrm{N}$ long: $77.47^{\circ} \mathrm{E}$ geographic; dip: $1.5^{\circ} \mathrm{N}$ ) and Tirunelveli (lat: $8.67^{\circ} \mathrm{N}$ long: $77.82^{\circ} \mathrm{E}$ geographic; dip: $0.5^{\circ} \mathrm{N}$ ) on a map of India along with the magnetic equator and the northern crest of the equatorial anomaly around $30^{\circ} \mathrm{N}$ dip. The $350-\mathrm{km}$ subionospheric points of the geostationary satellites FLEETSATCOM (lat: $21.10^{\circ} \mathrm{N}$ long: $87.25^{\circ} \mathrm{E}$ geographic; dip: $28.65^{\circ} \mathrm{N}$ ) and INMARSAT (lat: $21.08^{\circ} \mathrm{N}$ long: $86.59^{\circ} \mathrm{E}$ geographic; dip: $28.74^{\circ} \mathrm{N}$ ) from Calcutta are also indicated in this figure.

During the equinoxes August through October 2000, and February through April 2001, VHF scintillations recorded at Calcutta in the post-sunset hours were almost always saturated $\left(\mathrm{S}_{4} \sim 1\right)$. In this paper, geostationary L-band scintillations with $\mathrm{S}_{4 \max }>0.4(\mathrm{SI}(\mathrm{dB})>8)$ are considered. Geostationary L-band scintillations with $\mathrm{S}_{4 \max }>0.4(\mathrm{SI}>8 \mathrm{~dB})$ occurred on 33 nights during August through October 2000. The corresponding number for February through April 2001 was 45.

Samples of latitudinal variation of the equivalent vertical TEC measured using the plane-polarized transmission from LEO NOAA 14 on two consecutive days, 9 and 10 September 2000 are plotted in the top and bottom panel of Fig. 2a. The quasi-transverse (QT) propagation condition occurs when the satellite passes over $28^{\circ}-29^{\circ} \mathrm{N}$ latitude and the Faraday rotation angle attains a minimum value around those latitudes. To avoid the uncertainties of Faraday rotation in the QT region, the analysis was restricted to latitudes sufficiently south of the QT point. The 15-min $\mathrm{S}_{4}$ index for geostationary L-band scintillations observed at Calcutta on the two days mentioned above is shown in Fig. 2b. It may be observed from the top panel of Fig. 2a that the anomaly was remarkably developed on 9 September 2000 with a slope of 13.1 TEC units/degree. On this day, intense scintillations (L-band $\mathrm{S}_{4 \max } \sim 0.8$ ) were recorded at Calcutta. On the contrary, no scintillations were observed on 10 September 2000, a day with a much less latitudinal gradient of 6.1 TEC units/degree, as evident from the bottom panel of Fig. $2 b$.

Figures $3 \mathrm{a}$ and $\mathrm{b}$ show the latitudinal gradients of equivalent vertical TEC measured on different days of two equinoxes, August through October 2000, and February through April 2001. The filled-in circles correspond to days with $\mathrm{S}_{4 \max }>0.4$ at L-band whereas the crosses are for days with $\mathrm{S}_{4 \max }<0.4$. The correspondence between a developed equatorial anomaly and occurrence of scintillations in early evening hours was remarkable. From Fig. 3a, it is observed that days with a latitudinal gradient exceeding 8 TEC units/degree observed with NOAA 14 in the local afternoon 


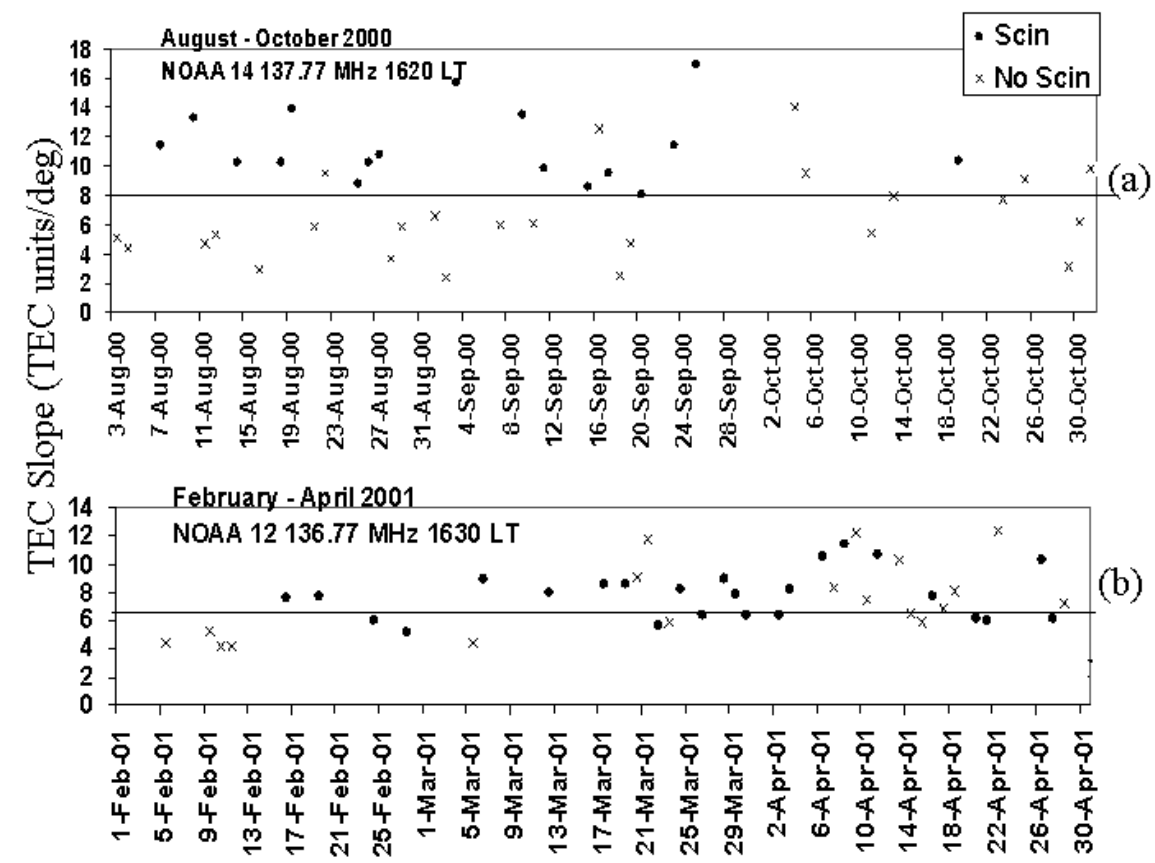

Fig. 3. Latitudinal gradients of Equivalent Vertical TEC (TEC Slope (TEC units/deg)) measured on different days of (a) August through October 2000 from LEO NOAA14 transmission at Calcutta. A "threshold" value of 8 TEC units/deg of the gradient, indicated by a horizontal line, shows a highly significant association with L-band scintillations (b) February through April 2001 from LEO NOAA12 transmission at Calcutta. A "threshold" value of 6 TEC units/deg of the gradient, indicated by a horizontal line, shows a highly significant association with L-band scintillations. In both figures, the circles correspond to days with L-band scintillations having $\mathrm{S}_{4 \max }>0.4$ whereas the crosses are for days with no L-band scintillations. LT=UT+06:00.

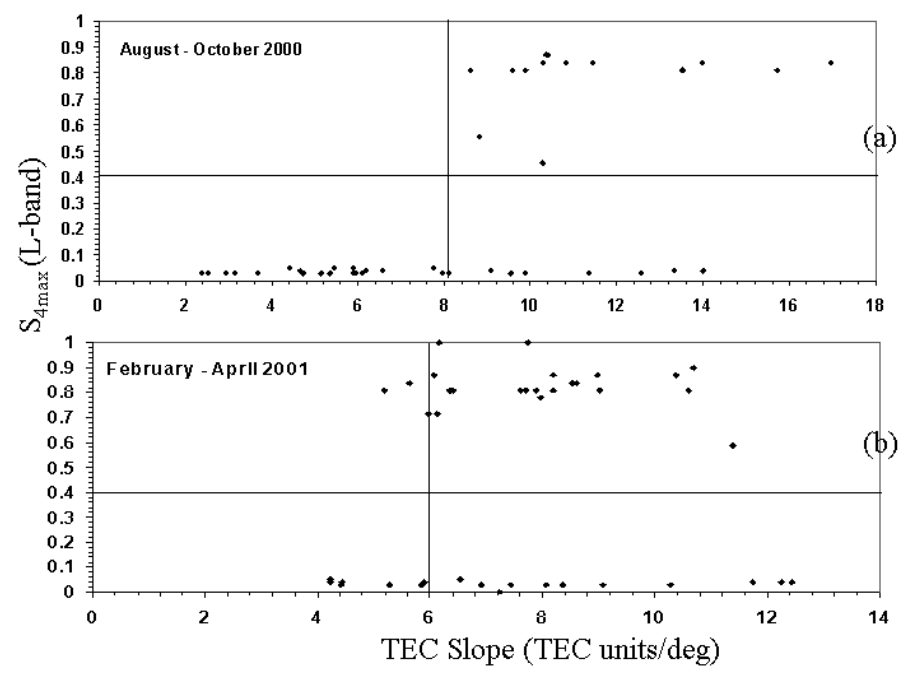

Fig. 4. Variation of maximum $\mathrm{S}_{4}\left(\mathrm{~S}_{4 \max }\right)$ at L-band and latitudinal gradient of Equivalent Vertical TEC (TEC Slope (TEC units/deg)) measured on different days of (a) August through October 2000 from LEO NOAA14 transmission at Calcutta. The "threshold" values of $\mathrm{S}_{4 \max }=0.4$ and TEC Slope $=8$ TEC units/deg for which a highly significant association is obtained are indicated by drawing lines. (b) February through April 2001 from LEO NOAA12 transmission at Calcutta. The "threshold" values of $\mathrm{S}_{4 \max }=0.4$ and TEC Slope $=6$ TEC units/deg for which a highly significant association is obtained are indicated by drawing lines. 
Table 1. $2 \times 2$ contigency table for testing the null hypothesis that a TEC Slope $>8$ TEC units/deg does not produce $\mathrm{S}_{4}$ max at L-band $>0.4$ i.e. the two parameters are not associated. The values shown in this table represents the common volume data of latitudinal gradient of TEC measured from LEO NOAA and $\mathrm{S}_{4}$ index for L-band geostationary scintillations.

\begin{tabular}{lccr}
\hline August-October 2000 & TEC Slope $>8$ TEC units/deg & TEC Slope $<8$ TEC units/deg & Total \\
\hline $\mathrm{S}_{4 \max }$ (L-band) $>0.4$ & 15 & 0 & 15 \\
$\mathrm{~S}_{4 \max }$ (L-band) $<0.4$ & 8 & 19 & 27 \\
& 23 & 19 & 42 \\
\hline & & & \\
\hline February-April 2001 & TEC Slope $>6$ TEC units/deg & TEC Slope $<6$ TEC units/deg & Total \\
\hline $\mathrm{S}_{4 \max }$ (L-band) $>0.4$ & 21 & 3 & 24 \\
$\mathrm{~S}_{4 \max }$ (L-band) $<0.4$ & 11 & 7 & 18 \\
& 32 & 10 & 42 \\
\hline
\end{tabular}

hours around 16:20 LT are more likely to experience intense L-band scintillations in the post-sunset hours. A significant association between the two phenomena was noted at $1 \%$ level by performing a chi-square test. Figure $3 \mathrm{~b}$ shows a threshold value of $6 \mathrm{TEC}$ units/deg for the latitudinal gradient of TEC measured from NOAA 12 around 16:30 LT for February through April 2001, corresponding to which a highly significant association was obtained at $1 \%$ level with L-band scintillations.

Variation of the anomaly gradients with L-band $\mathrm{S}_{4 \max }$ during the two equinoxes under consideration is presented in Figs. $4 \mathrm{a}$ and $\mathrm{b}$. On most of the days of August through October 2000, when the TEC slope exceeded 8 TEC units/deg, as indicated by the vertical line in Fig. $4 \mathrm{a}, \mathrm{S}_{4 \max }$ at L-band was greater than 0.4 . It has been found that there is a significant association at $1 \%$ level between a steep gradient of ionization in the local afternoon hours and post-sunset L-band scintillations. From Fig. 4b, it was found that during February through April 2001, the association between a TEC gradient in excess of 6 TEC units/deg and L-band $\mathrm{S}_{4 \max }>0.4$ is significant at $5 \%$ level. However in both equinoxes, there were occasions when a TEC slope greater than the threshold does not result in post-sunset L-band scintillations with $\mathrm{S}_{4 \max }>0.4$.

Table 1 presents a summary of the total number of cases associated with different values of TEC slope and corresponding $\mathrm{S}_{4 \max }$ at L-band, both measured from Calcutta during the two equinoxes under consideration. Since there appears to be a threshold value of the TEC slope, the cases are "binned" into two categories, namely, slope $>8$ TEC units/deg or $6 \mathrm{TEC}$ units/deg, and slope $<8 \mathrm{TEC}$ units/deg or 6 TEC units/deg (for August-October 2000 and FebruaryApril 2001, respectively). For each of these TEC slope bins, the $S_{4}$ measurements are placed into two categories, where $\mathrm{S}_{4}>0.4$ and $\mathrm{S}_{4}<0.4$. The results of "binning" could be seen in Table 1. During August through October 2000, when the latitudinal gradient of TEC in the afternoon hours was greater than 8 TEC units/deg, a forecast that the subsequent L-band $\mathrm{S}_{4 \max }$ would be greater than 0.4 was correct on $65 \%$ of the days. However, when the TEC gradient was less than 8 TEC units/deg, a forecast that $\mathrm{S}_{4 \max }$ at L-band would be less than 0.4 would be correct $100 \%$ of the time. For the period February through April 2001, when the latitudinal gradient of TEC in the afternoon hours was greater than 6 TEC units/deg, a forecast that post-sunset $\mathrm{S}_{4 \max }$ at L-band would be greater than 0.4 would be correct $66 \%$ of the time. However, when the TEC gradient was less than 6 TEC units/deg, a forecast that $\mathrm{S}_{4 \max }$ at L-band would be less than 0.4 would be correct $70 \%$ of the time. These results suggest that, on a night-tonight basis, it might be possible to forecast scintillation activity with a two to three hour lead-time. However during the period February through April 2001, the issue for concern is the $30 \%$ of "misses" i.e. occurrence of L-band scintillations (with $\mathrm{S}_{4 \max }>0.4$ ) with a negative forecast.

\subsection{Strength of equatorial electrojet and scintillations}

The daytime equatorial electrojet controls the development of the equatorial anomaly (Rastogi and Klobuchar, 1990) and it was suggested that a developed equatorial ionization anomaly in the daytime plays a crucial role in the subsequent development of F-region irregularities in the postsunset hours (Raghavarao et al., 1988). However, no idea about the pre-reversal enhancement of the $\boldsymbol{E} \times \boldsymbol{B}$ drift in the post-sunset hours can be obtained from magnetogram records since the electrojet current, which is conducting in nature, disappears in that local time interval. The enhanced electric field is attributed to the polarization effect due to the F-region dynamo (Rishbeth, 1971). The coupling between the $\mathrm{E}$ and $\mathrm{F}$ layers around the solar terminator has been explained as a spillover of the dayside equatorial electrojet into the F-layer (Haerendel and Eccles, 1992; Eccles, 1998), which causes the low-latitude plasma to rise. Diurnal plots of the strength of the equatorial electrojet $\Delta\left(\mathrm{H}_{T}-\mathrm{H}_{A}\right)$ 


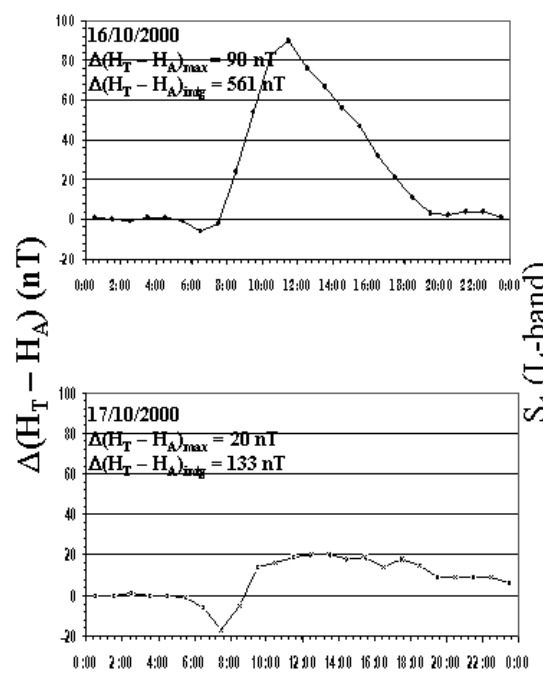

(a)

IST

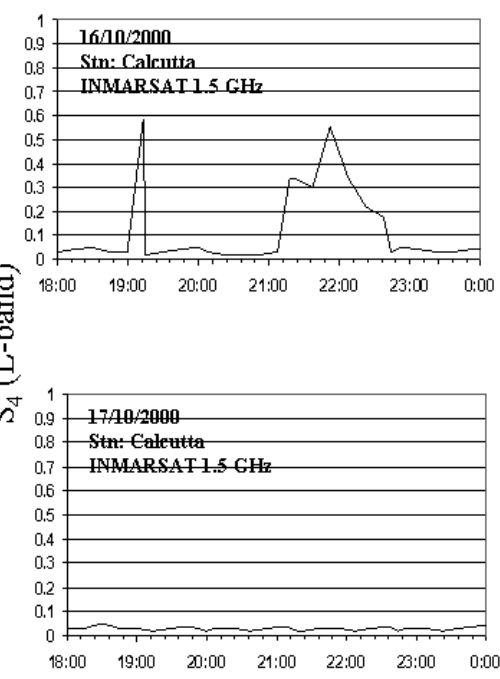

(b)

IST

Fig. 5. (a) Diurnal variation of the strength of the equatorial electrojet $\Delta\left(\mathrm{H}_{T}-\mathrm{H}_{A}\right)$ (nT) in the Indian longitude sector on two consecutive days, 16 and 17 October 2000. (b) Variation of $\mathrm{S}_{4}$ index of L-band scintillations at Calcutta on the above two days during 18:00 IST (=UT+05:30) to midnight.

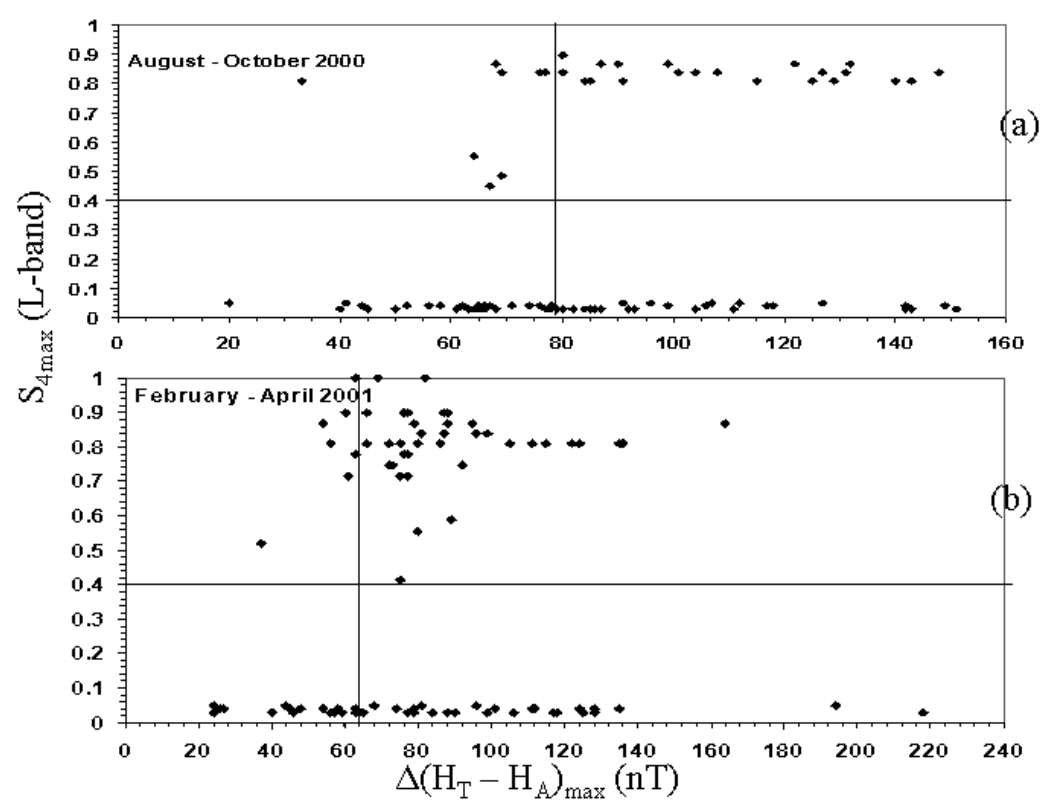

Fig. 6. Variation of maximum $\mathrm{S}_{4}\left(\mathrm{~S}_{4 \max }\right)$ at L-band with diurnal maximum value of $\Delta\left(\mathrm{H}_{T}-\mathrm{H}_{A}\right)\left(\Delta\left(\mathrm{H}_{T}-\mathrm{H}_{A}\right)_{\max }(\mathrm{nT})\right)$ in the Indian longitude sector measured on different days of (a) August through October 2000. The "threshold" values of $\mathrm{S}_{4 \max }=0.4$ and $\Delta\left(\mathrm{H}_{T}-\mathrm{H}_{A}\right)_{\max }=80 \mathrm{nT}$ for which a highly significant association is obtained are indicated by drawing lines. (b) February through April 2001. The "threshold" values of $\mathrm{S}_{4 \max }=0.4$ and $\Delta\left(\mathrm{H}_{T}-\mathrm{H}_{A}\right)_{\max }=65 \mathrm{nT}$ for which a highly significant association is obtained are indicated by drawing lines.

for 16 and 17 October 2000 are given in Fig. 5a. The corresponding $\mathrm{S}_{4}$ indices at L-band for the two nights are shown in Fig. 5b. On 16 October $2000 \Delta\left(\mathrm{H}_{T}-\mathrm{H}_{A}\right)_{\max }$ was $90 \mathrm{nT}$ while $\Delta\left(\mathrm{H}_{T}-\mathrm{H}_{A}\right)_{\text {intg }}$ was $561 \mathrm{nT}$. Post-sunset scintillations at L-band were recorded at Calcutta on that day with
$\mathrm{S}_{4 \max } \sim 0.6$. On the other hand, no scintillations were observed on 17 October 2000, a day with $\Delta\left(\mathrm{H}_{T}-\mathrm{H}_{A}\right)_{\max }=20 \mathrm{nT}$ and $\Delta\left(\mathrm{H}_{T}-\mathrm{H}_{A}\right)_{\text {int }}=133 \mathrm{nT}$.

Maximum $\mathrm{S}_{4}$ index at L-band on different nights of the two equinoxes are plotted in Figs. $6 \mathrm{a}$ and $\mathrm{b}$ against the 


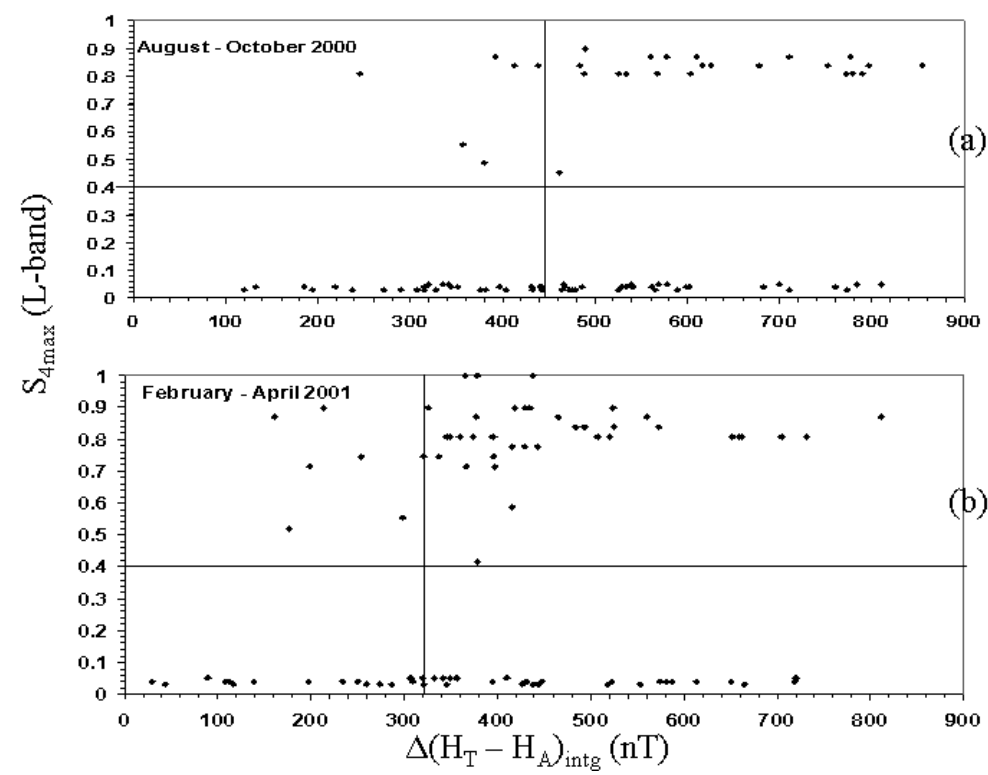

Fig. 7. Variation of maximum $\mathrm{S}_{4}\left(\mathrm{~S}_{4 \max }\right)$ at L-band with integrated value of $\Delta\left(\mathrm{H}_{T}-\mathrm{H}_{A}\right)\left[\Delta\left(\mathrm{H}_{T}-\mathrm{H}_{A}\right)\right.$ Intg. (nT)) in the Indian longitude sector measured on different days of (a) August through October 2000. The "threshold" values of $\mathrm{S}_{4 \max }=0.4$ and $\Delta\left(\mathrm{H}_{T}-\mathrm{H}_{A}\right)_{\text {int }} .=450 \mathrm{nT}$ for which a highly significant association is obtained are indicated by drawing lines. (b) February through April 2001. The "threshold" values of $\mathrm{S}_{4 \max }=0.4$ and $\Delta\left(\mathrm{H}_{T}-\mathrm{H}_{A}\right)_{\text {int }} .=320 \mathrm{nT}$ for which a highly significant association is obtained are indicated by drawing lines. In both the cases, the integration was performed from the time of onset of plasma transport to off-equatorial locations around 08 LT (=UT+06:00) till local sunset.

corresponding diurnal maximum values of $\Delta\left(\mathrm{H}_{T}-\mathrm{H}_{A}\right)$. A chi-square test was performed between $\Delta\left(\mathrm{H}_{T}-\mathrm{H}_{A}\right)_{\max }$ and the $\mathrm{S}_{4 \max }$ at L-band for the particular night. It was found that if a threshold value of $\Delta\left(\mathrm{H}_{T}-\mathrm{H}_{A}\right)_{\max }$ was set at $80 \mathrm{nT}$ during August through October 2000 corresponding to L-band $\mathrm{S}_{4 \max }=0.4$, a highly significant association at $1 \%$ level was obtained between the two phenomena. A similar degree of association was found during February through April 2001 if the threshold value of $\Delta\left(\mathrm{H}_{T}-\mathrm{H}_{A}\right)_{\max }$ was put to $65 \mathrm{nT}$. However, the reverse was not always true. It should be noted that these threshold values were selected with the aim of obtaining a high degree of association between the diurnal maximum of $\Delta\left(\mathrm{H}_{T}-\mathrm{H}_{A}\right)$ and $\mathrm{S}_{4 \max }$ at L-band.

The results were put in two categories: $\Delta\left(\mathrm{H}_{T}-\mathrm{H}_{A}\right)_{\max }$ $>80 \mathrm{nT}$ or $65 \mathrm{nT}$ and $\Delta\left(\mathrm{H}_{T}-\mathrm{H}_{A}\right)_{\max }<80 \mathrm{nT}$ or $65 \mathrm{nT}$ (for the two equinoxes under consideration). Following a procedure as described for Table 1, it was noted that a maximum value of $\Delta\left(\mathrm{H}_{T}-\mathrm{H}_{A}\right)>80 \mathrm{nT}$ during the day results in L-band $\mathrm{S}_{4 \max }>0.4$ in $46 \%$ of the time during August through October 2000. On the other hand, $\Delta\left(\mathrm{H}_{T}-\mathrm{H}_{A}\right)_{\max }<80 \mathrm{nT}$ produces $\mathrm{S}_{4 \max }$ at $\mathrm{L}$-band $<0.4$ in $81 \%$ of the time. The corresponding figures for February through April 2001 were 60\% and $76 \%$ respectively. The percentages of "misses" during these two equinoxes were $19 \%$ and $24 \%$, respectively.

A relation between the integrated value of $\Delta\left(\mathrm{H}_{T}-\mathrm{H}_{A}\right)$ and L-band $\mathrm{S}_{4 \max }$ at Calcutta on different days of August through October 2000, and February through April 2001 is presented in Figs. $7 \mathrm{a}$ and b. From Fig. $7 \mathrm{a}$, it is seen that $\Delta\left(\mathrm{H}_{T}-\mathrm{H}_{A}\right)_{\text {int }}$ in excess of $450 \mathrm{nT}$ generally results in $\mathrm{S}_{4 \max }>0.4$. The two phenomena showed a high degree of association at $1 \%$ significance level during August through October 2000. For the equinox of February through April 2001 (Fig. 6b), the threshold value of $320 \mathrm{nT}$ for the integrated value of $\Delta\left(\mathrm{H}_{T}-\mathrm{H}_{A}\right)$ produces a highly significant association at $1 \%$ level with $\mathrm{S}_{4 \max }>0.4$.

As before, the data was classified into two categories: $\Delta\left(\mathrm{H}_{T}-\mathrm{H}_{A}\right)_{\text {int }}>450 \mathrm{nT}$ or $320 \mathrm{nT}$ and $\Delta\left(\mathrm{H}_{T}-\mathrm{H}_{A}\right)_{\text {int }}$ $<450 \mathrm{nT}$ or $320 \mathrm{nT}$ (for August-October 2000 and February through April 2001, respectively). During August through October 2000 , a forecast that $\Delta\left(\mathrm{H}_{T}-\mathrm{H}_{A}\right)_{\text {int }}>450 \mathrm{nT}$ produces a post-sunset L-band $\mathrm{S}_{4 \max }>0.4$ was found to be true $46 \%$ of the time while $\Delta\left(\mathrm{H}_{T}-\mathrm{H}_{A}\right)_{\text {int }}<450 \mathrm{nT}$ produces a subsequent L-band $\mathrm{S}_{4 \max }<0.4$ on $82 \%$ of the time. For February through April 2001, the corresponding figures were $61 \%$ and $75 \%$, respectively. L-band scintillations without a forecast, based on the integrated value of $\Delta\left(\mathrm{H}_{T}-\mathrm{H}_{A}\right)$, occurred $18 \%$ and $25 \%$ of the time respectively for the abovementioned two equinoxes.

3.3 Post-sunset F-region height rise over the magnetic equator and scintillations

Generation of equatorial irregularities over the magnetic equator in the post sunset hours is intimately related to the variation of height of the F-layer around sunset (Farley et al., 


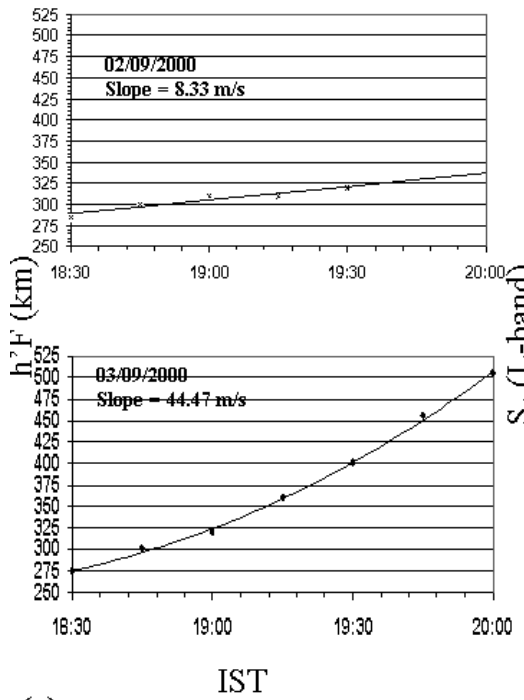

(a)
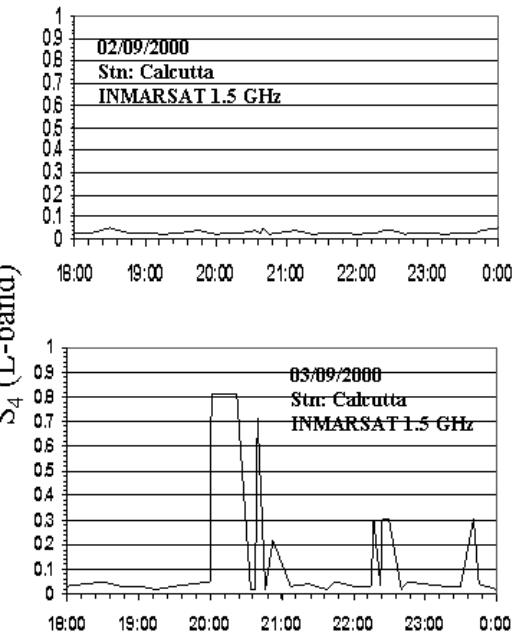

(b)
IST

Fig. 8. (a) Vertical drift velocity $\left(h^{\prime} F\right.$ Slope $\left.(\mathrm{m} / \mathrm{s})\right)$ of F-region measured at Kodaikanal on two consecutive days 2 and 3 September 2000 in the post-sunset hours till the upward movement stops. (b) Variation of $\mathrm{S}_{4}$ index of L-band scintillations at Calcutta on the above two days during 18:00 IST (=UT+05:30) to midnight.

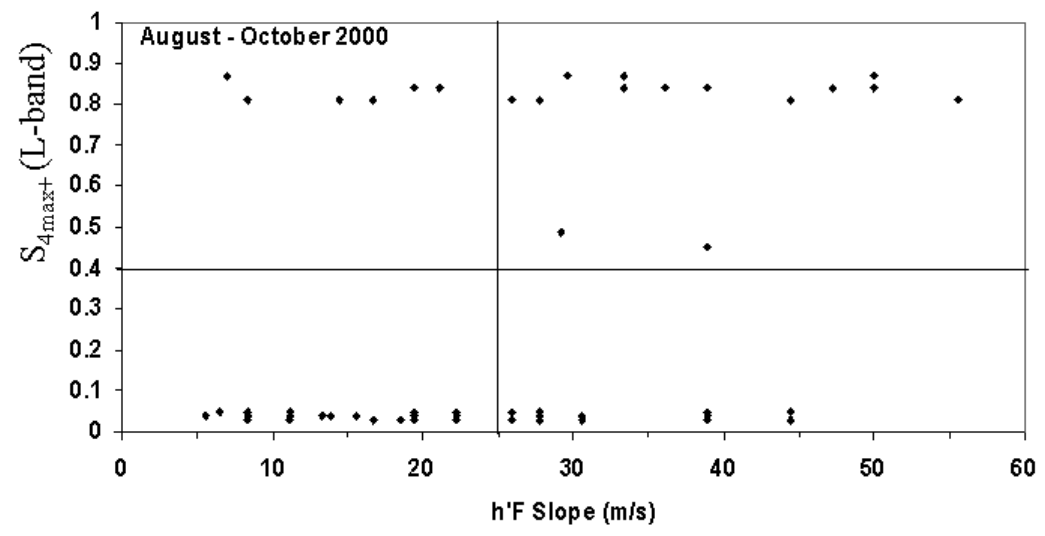

Fig. 9. Variation of maximum $\mathrm{S}_{4}\left(\mathrm{~S}_{4 \max }\right)$ at L-band measured at Calcutta and vertical drift velocity $\left(h^{\prime} F\right.$ Slope $\left.(\mathrm{m} / \mathrm{s})\right)$ measured at Kodaikanal on different days of August through October 2000. The "threshold" values of $\mathrm{S}_{4 \mathrm{max}}=0.4$ and $h^{\prime} F$ Slope $=25 \mathrm{~m} / \mathrm{s}$ for which a highly significant association is obtained are indicated by drawing lines.

1970; Abdu et al., 1981). It was established that a sharp rise of F-region altitude due to the pre-reversal enhancement of the eastward electric field is often followed by the generation of intense irregularities through Rayleigh-Taylor instability mechanism. Samples of $h^{\prime} F$ for two days, 2 and 3 September 2000, obtained from the Kodaikanal ionosonde are plotted in Fig. 8a. The corresponding L-band $\mathrm{S}_{4}$ indices measured at Calcutta are shown in Fig. 8b. The temporal slope of $h^{\prime} F$ ( $\mathrm{d} h^{\prime} F / \mathrm{dt}$ ) was calculated over the time interval from local sunset till the height reaches its maximum value (normally around 20:30 LT). On 2 September 2000, the F-layer height rise was sluggish $\sim 8 \mathrm{~m} / \mathrm{s}$ corresponding to which no scintil- lations were observed at Calcutta. On the contrary, $\mathrm{d} h^{\prime} F / \mathrm{dt}$ was very sharp next day on 3 September $2000 \sim 44 \mathrm{~m} / \mathrm{s}$ with $\mathrm{S}_{4 \max } \sim 0.8$.

The temporal slope of $h^{\prime} F$ on individual days of August through October 2000 is plotted in Fig. 9 to study the correspondence between the post-sunset F-region height rise over the magnetic equator from Kodaikanal and the intensity of post-sunset geostationary L-band scintillations (indicated by the maximum $\mathrm{S}_{4}$ index) obtained from the satellite beacon records at Calcutta. It could be seen that on a number of days, when the upward drift of the $F 2$ layer over Kodaikanal exceeded $25 \mathrm{~m} / \mathrm{s}$, geostationary L-band scintillations with 


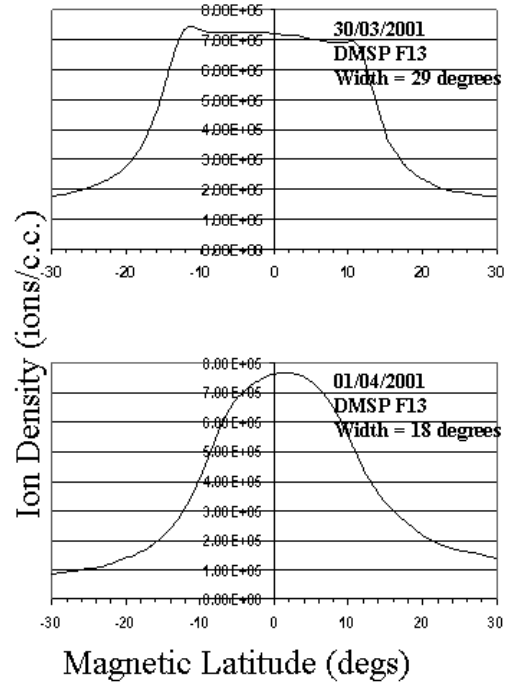

(a)

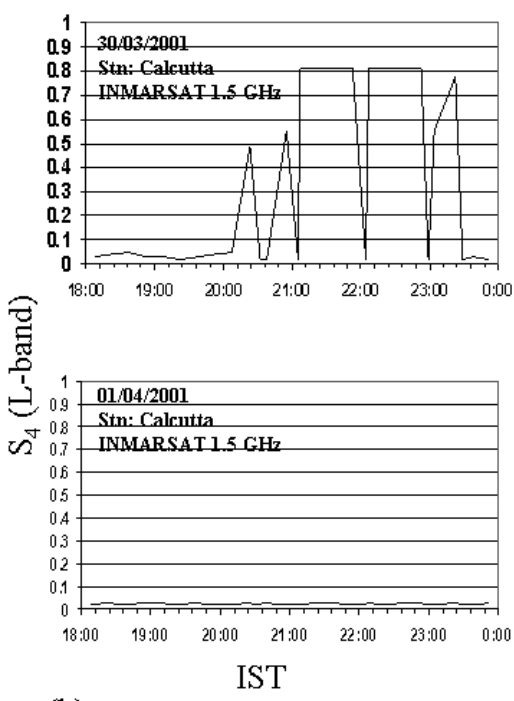

(b)

Fig. 10. (a) Variation of ionization distribution with magnetic latitude within $\pm 30^{\circ}$ on two days, 30 March 2001 (flat-topped latitudinal distribution) and 1 April 2001 (round-topped latitudinal distribution) measured from DMSP F13 satellite around sunset. (b) Variation of $\mathrm{S}_{4}$ index of L-band scintillations at Calcutta on the above two days during 18:00 IST (=UT+05:30) to midnight.

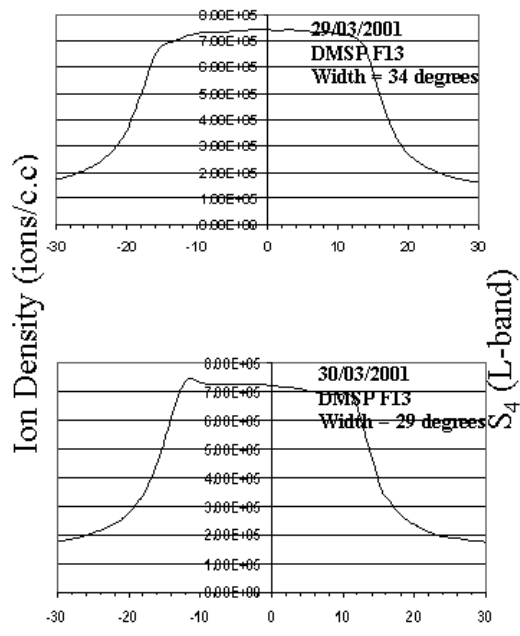

(a)
Magnetic Latitude (degs)
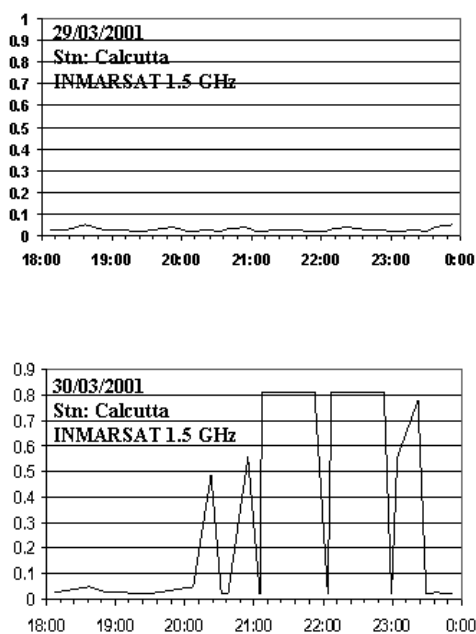

(b)

IST

Fig. 11. (a) Variation of ionization distribution with magnetic latitude within $\pm 30^{\circ}$ on two consecutive days, 29 and 30 March 2001 measured from DMSP F13 satellite around sunset. Ionization distribution was flat-topped on both these days. (b) Variation of $\mathrm{S}_{4}$ index of L-band scintillations at Calcutta on the above two days during 18:00 IST (=UT+05:30) to midnight.

$\mathrm{S}_{4 \max }>0.4$ were recorded at Calcutta. An association at a significance level of $5 \%$ is noted between the two events. Classifying the $h^{\prime} F$ slopes into two categories, one greater than $25 \mathrm{~m} / \mathrm{s}$ and the other less than $25 \mathrm{~m} / \mathrm{s}$, it was found that a forecast that a $h^{\prime} F$ slope $>25 \mathrm{~m} / \mathrm{s}$ would produce L-band $\mathrm{S}_{4 \max }>0.4$ was true $43 \%$ of days. On the other hand, a forecast that $h^{\prime} F$ slope $<25 \mathrm{~m} / \mathrm{s}$ would result in L-band $\mathrm{S}_{4 \max }<0.4$ was valid $80 \%$ of the time. The "misses" i.e. occurrence of L-band geostationary scintillations (with $\mathrm{S}_{4 \max }>0.4$ ) without a forecast occurred $20 \%$ of the cases.

Anderson et al. (2004) reported a threshold value of $20 \mathrm{~m} / \mathrm{s}$ for the F-region upward drift when UHF $\mathrm{S}_{4}$ index greater 


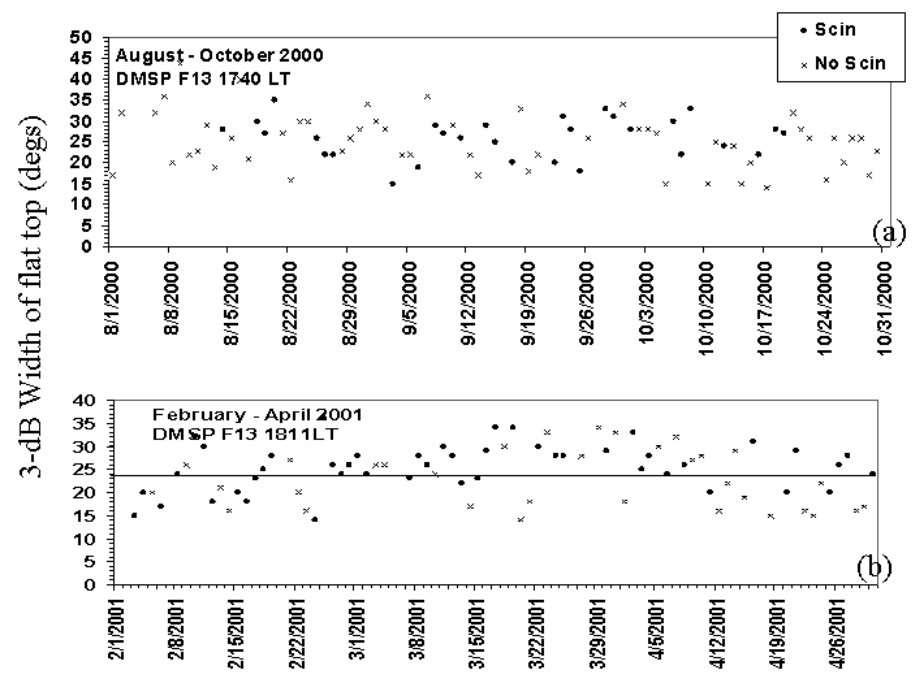

Fig. 12. 3-dB width (width at $70 \%$ of the maxima) of ionization density distribution (Width of flattop (degs)) measured by DMSP F13 satellite within $\pm 30^{\circ}$ magnetic latitude in the Indian longitude sector on different days of (a) August through October 2000. No suitable "threshold" value of the width is found for this period. (b) February through April 2001. A horizontal line at 24 deg indicates the "threshold" value of the width of the flat-topped ionization distribution for which a highly significant association is obtained. In both the figures, the circles correspond to days with L-band scintillations having $S_{4 \max }>0.4$ whereas the crosses are for days with no L-band scintillations. $\mathrm{LT}=\mathrm{UT}+06: 00$.

than 0.5 was expected in the Peruvian/Chilean longitude sector during 1998-1999. The relationship between UHF and L-band $\mathrm{S}_{4}$ indices is not linear. At locations like Calcutta, near the crest of the equatorial anomaly, UHF scintillation is normally saturated when $\mathrm{S}_{4}$ at L-band is greater than 0.4. From simultaneous observations at UHF and L-band, an idea about $\mathrm{S}_{4}$ at L-band can be obtained from the autocorrelation distance or fading rate at UHF. When the autocorrelation distance of the UHF ground diffraction scintillation pattern is small, or the fading rate at UHF is fast, L-band scintillation index is high.

3.4 Latitudinal distribution of topside ionization and scintillations

Existence of a flat-topped ionization distribution over the magnetic equator around sunset has been suggested as a possible indication of occurrence of post-sunset scintillations (Basu et al., 2002). In order to quantify the relation between the two, the 3-dB width of the flattop (width of flattop calculated at $70 \%$ of the maxima) is suggested to be a precursor in the present paper. Samples of ion density as a function of magnetic latitude for 30 March and 1 April 2001 obtained from DMSP F13 around local sunset (17:40 LT) at Calcutta within the magnetic latitude range $\pm 30^{\circ}$ are shown in Fig. 10a. $\mathrm{S}_{4}$ index for geostationary L-band scintillations recorded at Calcutta on the two days are plotted in Fig. 10b. A flat-topped ionization density profile around the magnetic equator with a 3-dB width of $29 \mathrm{deg}$ was found on $30 \mathrm{March}$ 2001. This was followed by intense scintillation activity on the INMARSAT link with $\mathrm{S}_{4 \max } \sim 0.8$ in the post-sunset to midnight local time sector. However, on 1 April 2001, the latitudinal distribution was round-topped with a 3-dB width of $18 \mathrm{deg}$. No scintillations were recorded on that night at L-band. The nature of these plots agree fairly well with that described by earlier workers (Basu et al., 2002).

However a flat-topped ionization profile over the magnetic equator may not always be associated with subsequent Lband scintillations. Figures 11a and b display one such case observed on 29 March and 30 March 2001. On both these days a flat-topped latitudinal distribution of ionization density were obtained with $3-\mathrm{dB}$ widths of $34 \mathrm{deg}$ and $29 \mathrm{deg}$, respectively. While 30 March 2001 saw intense L-band scintillations as mentioned earlier, no such events were noted on 29 March 2001.

Figures $12 \mathrm{a}$ and $\mathrm{b}$ show the $3-\mathrm{dB}$ width of the ionization density distribution on different days of the equinoctial period August through October 2000 and February through April 2001. The filled-in circles correspond to days with scintillations whereas the crosses represent days without scintillations. No suitable threshold width having a close correlation with L-band scintillations having $\mathrm{S}_{4 \max }>0.4$ was found in Fig. 12a. From Fig. 12b, a threshold width of $24^{\circ}$ of the flat top was found to be significant at $2.5 \%$ with L-band scintillations having $\mathrm{S}_{4 \max }>0.4$.

Table 2 presents an average comparative performance of the different forecasting techniques over the two equinoxes August through October 2000 and February through April 2001. Of all the techniques, measurement of the 
Table 2. Comparative performance of the different forecasting techniques obtained by averaging the results for the two equinoxes, August-October 2000 and Febraury-April 2001.

\begin{tabular}{lcccc}
\hline & $\begin{array}{l}\text { Correct forecasting of } \\
\text { occurrence of } \\
\text { geostationary L-band } \\
\text { scintillations } \\
\text { with } \mathrm{S}_{4 \mathrm{max}}>0.4\end{array}$ & $\begin{array}{l}\text { Correct forecasting of } \\
\text { non-occurrence of } \\
\text { geostationary L-band } \\
\text { scintillations } \\
\text { with } \mathrm{S}_{4 \text { max }}>0.4\end{array}$ & $\begin{array}{l}\text { Occurrence of } \\
\text { geostationary L-band } \\
\text { scintillations with } \\
\mathrm{S}_{4 \text { max }} \text { (L-band) }>0.4 \\
\text { without a forecast i.e. } \\
\text { "Misses" }\end{array}$ & $\begin{array}{l}\text { Non-occurrence of } \\
\text { geostationary L-band } \\
\text { scintillations with } \\
\text { with } \mathrm{S}_{4 \text { max }}>0.4 \\
\text { despite a forecast } \\
\text { i.e. "False Alarm" }\end{array}$ \\
\hline $\begin{array}{l}\text { Forecasting using TEC Slope } \\
\text { measured from LEO NOAA }\end{array}$ & $65 \%$ & $85 \%$ & $15 \%$ & $35 \%$ \\
\hline $\begin{array}{l}\text { Forecasting using } \\
\text { geomagnetic data }\end{array}$ & $53 \%$ & $79 \%$ & $22 \%$ & $47 \%$ \\
\hline $\begin{array}{l}\text { Forecasting using } \\
\text { ionosonde } h^{\prime} F \text { data }\end{array}$ & $43 \%$ & $80 \%$ & $20 \%$ & $57 \%$ \\
\hline
\end{tabular}

latitudinal gradient of TEC from LEO NOAA transmission provides the best results with a successful forecasting in $65 \%$ and $85 \%$ cases for occurrence and non-occurrence of scintillations respectively.

\section{Summary and discussions}

This paper presents, perhaps for the first time, a quantitative relation between the different suggested precursors of ionospheric irregularities and actual occurrence of postsunset equatorial F-region scintillations during the equinoctial months of the last solar maximum in 2000-2001. Since the equatorial ionosphere produces very intense saturated scintillations even at L-band in the early evening hours, failures of satellite-based communication and navigation systems are frequently encountered in this region with the worstcase figures coming from stations situated near the crests of the equatorial anomaly. The results presented in this paper, though not foolproof, provide some insight towards development of forecasting and nowcasting techniques for the equatorial ionosphere under the International Space Weather program.

It has been suggested that "bubbles" in the post sunset hours are more probable on days when the daytime anomaly is more developed (Raghavarao et al., 1988), although the interconnection between the two phenomena is yet to be fully understood. The coupling between the $\mathrm{E}$ and $\mathrm{F}$ layers in the vicinity of the solar terminator has been worked out by Haerendel and Eccles (1992) and Eccles (1998). According to this model, a portion of the dayside equatorial electrojet spills over into the F-layer and causes the low-latitude plasma to rise in the early post sunset hours.

The equatorial anomaly is not confined to the maximum ionization height $h m \mathrm{~F} 2$, but extends up to several hundred kilometers in the topside of the ionosphere. Measurements of latitudinal gradient of electron content from LEO satellite transmissions have established that the TEC exhibits features similar to that of the anomaly. The present study clearly establishes that days with developed equatorial anomaly in the afternoon, as indicated by the gradient of TEC, are more likely to be followed by generation of intense equatorial bubbles resulting in L-band scintillations near the crests of the equatorial anomaly during the local post sunset to midnight hours.

In the present paper, parameters obtained from different techniques have been suggested as precursors to post sunset equatorial scintillations on transionospheric geostationary links. These methods could be summarized as:

- Measuring the latitudinal gradient of the TEC in the region between the trough and the crest of the equatorial anomaly from the Faraday rotation of a plane polarized signal from a low Earth orbiting satellite.

- Calculating the diurnal maximum and integrated value (the integration being performed from the time of onset of plasma influx from the magnetic equator to offequatorial latitudes around 08 LT till local sunset) of the strength of the equatorial electrojet in the Indian longitude sector.

- Estimation of the post sunset F-region height rise over the magnetic equator from local sunset till 20:00 LT when the vertical rise of $h^{\prime} F$ stops

- Determination of the width of the flat top from the latitudinal distribution of ionization density in the topside F-region obtained from satellites like DMSP.

It should be noted that in all the above techniques, the threshold values quoted were obtained exclusively with a view to finding a high degree of correlation between any one of the 
precursors and the occurrence of post sunset scintillations by performing a chi-square test.

It is found that the successful forecasting of the occurrence of post sunset scintillations is always less than a correct forecasting of their non-occurrence. This suggests the existence of other drivers/ physical mechanisms responsible for triggering the generation of F-region irregularities. The success percentage of forecasting scintillations using Faraday rotation technique is about $65 \%$ (averaging the results obtained during the two equinoxes), which is higher compared to other techniques. The percentages of "false alarms" i.e. non-occurrence of scintillations in spite of a forecast is the lowest in this method. These cases should also be kept in mind while comparing the different techniques as they introduce wastage of resources of any communication and navigation system. However the issue of serious concern is the percentage of "misses" i.e. occurrence of intense $\left(\mathrm{S}_{4 \max }>0.4\right)$ scintillations without a forecast. The percentage of "misses" is also least ( $15 \%$ when averaged over the two equinoxes) when using a technique for measurement of Total Electron Content with a LEO satellite transmission for calculating the anomaly gradient.

The suggestion that an idea about the occurrence of scintillations may be obtained from the latitudinal distribution of ion density by DMSP (Basu et al., 2002) is also examined. During the period of observation of the present study, it has been observed that although the probability of occurrence of scintillations is high on days with flat-topped ion density variation over the magnetic equator, there are cases when no scintillations are observed even when a pronounced flat top variation was recorded.

Among all the different measures, determination of the latitudinal gradient of TEC provides the most reliable precursor for post-sunset equatorial scintillations. It has the highest percentage of correct forecasting of occurrence as well as non-occurrence of scintillations on a particular night along with the lowest percentage of "misses" and "false alarms" as evident from Table 2. TEC could be measured by different techniques like Faraday Rotation of a plane-polarized signal, differential Doppler measurement or tomography. However, the Faraday Rotation technique is the most simple and inexpensive method for measuring the TEC.

Acknowledgements. This research has been sponsored in part by the Indian Space Research Organization (ISRO) through the S. K. Mitra Center for Research in Space Environment, University of Calcutta. Magnetic data have been obtained from the prompt geomagnetic data reports published by the Indian Institute of Geomagnetism (IIG). J. H. Sastri was kind enough to provide the Kodaikanal ionosonde data. The authors gratefully acknowledge the Center for Space Sciences at the University of Texas at Dallas and the U.S. Air Force for providing the DMSP thermal plasma data via the web site http://cindispace.utdallas.edu/DMSP/.

Topical Editor M. Pinnock thanks D. N. Anderson and R. Leitinger for their help in evaluating this paper.

\section{References}

Abdu, M. A., Batista, I. S., and Bittencourt, J. .: Some characteristics of spread-F at the magnetic equatorial station Fortaleza, J. Geophys. Res., 86, 6836-6842, 1981.

Anderson, D. N., Reinisch, B., Valladare, C., Chau, J., and Veliz, O.: Forecasting the occurrence of ionospheric scintillation activity in the equatorial ionosphere on a day-to-day basis, J. Atmos. Sol. Terr. Phys., 66, 1567-1572, 2004.

Basu, S. and DasGupta, A.: Latitude variation of Total Electron Content in equatorial region, J. Geophys. Res., 72, 5555-5558, 1967.

Basu, S. and Basu, Su.: Scintillation technique for probing ionospheric irregularities, in WITS Handbook, vol. 2, edited by: Liu, C. H., SCOSTEP, Univ. of Ill., Urbana, 128-136, 1989.

Basu, S., Groves, K. M., Basu, Su., and Sultan, P. J.: Specification and forecasting of scintillations in communication/navigation links: current status and future plans, J. Atmos. Sol. Terr. Phys., 64, 1745-1754, 2002.

Eccles, J. V.: A simple model of low-latitude electric fields, J. Geophys. Res., 103, 26 699-26 708, 1998.

Farley, D. T., Balsley, B. B., Woodman, R. F., and McClure, J. P.: Equatorial spread F: implications of VHF radar observations, J. Geophys. Res., 75, 7199-7216, 1970.

Haerendel, G. and Eccles, J. V.: The role of the equatorial electrojet in the evening ionosphere, J. Geophys. Res., 97, 1181-1192, 1992.

Kane, R. P.: Comparison of geomagnetic changes in India and the POGO data, J. Atmos. Terr. Phys., 35, 1249-1252, 1973.

Kelley, M. C.: The earth's ionosphere, Academic Press, Inc., 1989.

Rastogi, R. G. and Klobuchar, J. A.: Ionospheric electron content within the equatorial $F_{2}$ layer anomaly belt, J. Geophys. Res., 95, 19045-19052, 1990.

Ragahavarao, R., Nageswararao, M., Hanumath Sastri, J., Vyas, G. D., and Sriramarao, M.: Role of equatorial ionization anomaly in the initiation of equatorial spread-F, J. Geophys. Res., 93, 5959_ 5964, 1988.

Rishbeth, H.: Polarization fields produced by winds in the equatorial F-region, Planet. Space. Sci., 19, 357-369, 1971.

Whitney, H. E., Aarons, J., and Malik, C.: A proposed index for measuring ionospheric scintillations, Planet. Space. Sci., 17, 1069-1073, 1969. 